Canadian

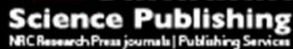

Canadian Geotechnical Journal Revue canadienne de géotechnique

\title{
Optimal Profile for Concave Slopes under Static and Seismic Conditions
}

\begin{tabular}{|r|l|}
\hline Journal: & Canadian Geotechnical Journal \\
\hline Manuscript ID & cgj-2016-0057.R1 \\
\hline Manuscript Type: & Article \\
\hline Date Submitted by the Author: & 04-Apr-2016 \\
\hline Complete List of Authors: & $\begin{array}{l}\text { Vahedifard, Farshid; Mississippi State University, Department of Civil and } \\
\text { Environmental Engineering } \\
\text { Shahrokhabadi, Shahriar; Mississippi State University } \\
\text { Leshchinsky, Dov; University of Delaware }\end{array}$ \\
\hline Keyword: & Slope stability, Limit equilibrium, Concave slope, Optimization, Seismicity \\
\hline
\end{tabular}




\title{
Optimal Profile for Concave Slopes under Static and Seismic Conditions
}

\author{
Farshid Vahedifard ${ }^{1}$, Shahriar Shahrokhabadi ${ }^{2}$, Dov Leshchinsky ${ }^{3}$
}

1 Corresponding Author, Assistant Professor, Department of Civil and Environmental Engineering, Mississippi State University, Mississippi State, MS 39762, USA. email: farshid@cee.msstate.edu

2 Graduate student, Department of Civil and Environmental Engineering, Mississippi State University, Mississippi State, MS 39762, USA. email: ss2804@msstate.edu

${ }^{3}$ Professor Emeritus, Dept. of Civil and Environmental Engineering, University of Delaware, Newark, DE 19716, and Consultant, ADAMA Engineering, Inc. 12042 SE Sunnyside Rd., Suite 711, Clackamas, Oregon 97015, USA. email: dov@udel.edu

\begin{abstract}
This study presents a methodology to determine the stability and optimal profile for slopes with concave cross section under static and seismic conditions. Concave profiles are observed in some natural slopes suggesting that such geometry is a more stable configuration. In this study, the profile of a concave slope was idealized by a circular arc defined by a single variable, the Mid-Chord Offset (MCO). The proposed concave profile formulation was incorporated into a limit equilibrium-based log spiral slope stability method. Stability charts are presented to show the stability number, MCO, and mode of failure for homogeneous slopes corresponding to the most stable configuration under static and pseudostatic conditions. It is shown that concave profiles can significantly improve the stability of slopes. Under seismic conditions, the impact of concavity is most pronounced. Good agreement was demonstrated upon comparison of the results from the proposed method against those attended from a rigorous upper bound limit analysis. The proposed methodology, along with recent advances in construction technology, can be employed to use concave profiles in trenches, open mine excavations, earth retaining systems, and cemented/stabilized soil slopes. The results
\end{abstract}


presented provide a useful tool for preliminary evaluation for adopting such concave profiles in practice.

Keywords: Slope stability; Limit equilibrium; Concave slope; Optimization; Seismicity.

\section{Notation}
$A_{1} \quad$ Log spiral constant
C Design cohesion
FS Factor of safety
$\mathrm{H} \quad$ Slope height
I Arc angle
$k_{h}, k_{v} \quad$ Horizontal and vertical seismic coefficients
LC Long cord
MCO Mid-Chord Offset
$N \quad$ Global stability number
$N_{i} \quad$ Local stability number
PC Entry point for circular arc
$\mathrm{PI} \quad$ Intersection of back and forward tangent
PT Exit point for circular arc
$\mathrm{R}_{\mathrm{c}} \quad$ Arc radius
$\mathrm{R}_{\mathrm{L}} \quad$ Log spiral radius
W Weight of failure mass
$x \quad \mathrm{x}$-coordinate of any point along the curved slope profile
$x_{c c} \quad \mathrm{x}$-coordinate of the center of the curved slope profile
$x_{F} \quad \mathrm{x}$-coordinate of any point along the log spiral failure surface
$x_{C G} \quad \mathrm{x}$-coordinate of the center of gravity of the failure mass
$x_{C L} \quad \mathrm{x}$-coordinate of the pole of log spiral
y $\quad y$-coordinate of any point along the curved slope profile
$y_{c c} \quad \mathrm{y}$-coordinate of the center of the curved slope profile
$Y_{e} \quad$ Height where the slip surface exits the slope facing profile
$y_{F} \quad y$-coordinate of any point along the log spiral failure surface
$y_{C G} \quad \mathrm{y}$-coordinate of the center of gravity of the failure mass 


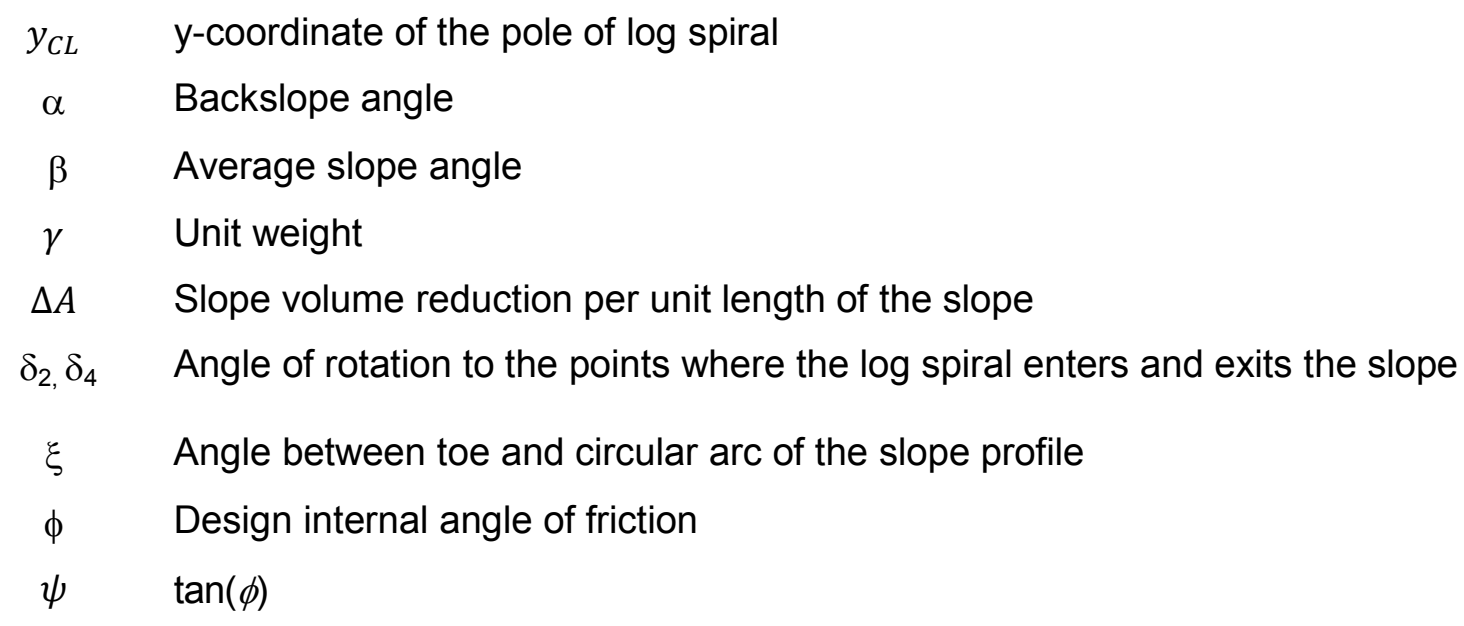

\section{Introduction}

Engineered slopes and earth structures are commonly built with a planar profile in cross section. However, it has been shown that concave slopes offer higher stability (e.g., Sokolovskil 1960; Utili and Nova 2007; Jeldes et al. 2013) and better erosion resistance (e.g., Rieke-Zapp and Nearing 2005; Schor and Gray 2007; Jeldes et al. 2014) when compared with the equivalent planar slopes. Utili and Nova (2007) demonstrated the higher stability of concave slopes and argued that such higher stability may also explain the concave shape of perimeter walls of some typical Japanese castles (Nishida et al. 2005; Utili and Nova 2007). Moreover, natural slopes with concave profiles can often be seen further implying that concave slopes are an efficient outcome of geomorphological evolutionary processes (e.g., Gray 2013). Fig. 1 shows an example of a natural concave slope located on US-101, north of the Alsea Bay Bridge in Waldport, Oregon. Recent advances in auto-guided construction equipment along with increased precession in three-dimensional mapping technology allow and facilitate construction of such concave profiles in engineered slopes and earth structures (Jeldes et al. 2013; Jeldes et al. 2014). For geosynthetic-reinforced soil structures, Vahedifard et al. (2016a) showed that 
using concave facing profiles can decrease the required tensile strength of the reinforcement by up to $30 \%$ under static and seismic conditions.

Few attempts have been made to analyze concaves slopes and to quantify the contribution of such concave profiles to stability and erosion resistance of earthen slopes (e.g., Sokolovskiĭ 1960; Utili and Nova 2007; Jeldes et al. 2013; Gray 2013). Sokolovskiĭ (1960) used the slip-line field theory and showed that the slope surface at the limit equilibrium (LE) state has a concave profile. Sokolovskii (1960) used the method of characteristics to solve the equations of limiting stresses. His solution leads to two differential equations, referred to as characteristic equations, to describe the direction of the slip lines (Sokolovskii 1960). This method involves a rigorous numerical solution for frictional soil with non-zero unit weight. Jeldes et al. (2013) used the Sokolovskiĭ solution for a weightless medium and presented an approximate solution which transformed Sokolovskiî's differential equations into a hyperbolic expression representing the optimal concave profile of slope. Jeldes et al. (2014) used the latter approximate solution along with an erosion model and showed that concave slopes yield $15-40 \%$ less sediment than alternative planar slopes with the same factor of safety. Utili and Nova (2007) used two log spirals: one spiral to represent the concave slope profile and the other for the slip surface, in the context of the upper bound limit analysis (LA) method. Utili and Nova (2007) presented a series of stability charts and showed that concave slopes can significantly enhance stability. All the aforementioned methods only considered a level backslope and static condition.

This study presents a methodology to determine the stability number and optimal profile of concave slopes. The concave slope profile is idealized using a circular arc defined by a single variable, the Mid-Chord Offset (MCO). There are several features which distinguish the proposed formulation from alternative formulations: a) Using MCO as a practical approximation of constructible concavity in a LE-based slope stability formulation, b) modifying LE-based log spiral slope stability formulation to deal with concave slopes, c) considering non-horizontal 
backfills, and d) including horizontal and vertical seismic coefficients in the stability analysis of concave slopes.

\section{Formulation and Proposed Framework}

Optimizing a slope profile can help to achieve a more stable slope and, potentially, more economical design. Usually the locations of toe and crest are prescribed by the project. Consequently, optimization is subjected to geometrical constraints. In the following sections, the slope surface for given height and soil properties is formulated using a circular arc defined by a single parameter, MCO (see Fig. 2b). The formulation of the concave facing is used along with a LE-based log spiral slope stability formulation. For each slope, the proposed formulation and solution procedure can be used to obtain the stability number for various MCO values. Depending upon the designer's preference, the optimal slope profile can be defined as the profile that yields the most stable slope or the profile which results in the largest stable concavity, or a combination of both. A designer needs to consider economical aspects and technical needs of the project in order to define the most appropriate MCO and optimal slope profile.

Along with continuous advances in construction technology and equipment, the proposed concave profiles for engineered slopes can be used in practice for native soils in applications such as cut slopes, trenches, open mine excavations, or when cohesion and/or an equivalent support system can legitimately be used for long term design purposes. Potential applications may include rock slopes, earth retaining systems (e.g., Vahedifard et al. 2016a), cemented/stabilized fill slopes. Cohesion should be accounted for design purposes with great caution and only when its value can be reliably assessed during the life span of the slope (e.g., in cemented soils or native soils). Several design guidelines do not recommend use of cohesion in design, primarily due to significant uncertainties associated with the determination of a reliable apparent cohesion value as well as its tendency to vanish with a change in the degree 
of saturation (e.g., Leshchinsky and Tatsuoka 2013; Vahedifard et al. 2014; Vahedifard et al. 2016b).

\section{Formulation of Concave Facing Profile using MCO}

Fig. 2 shows the notation and details of the circular arc geometry which is used to represent the concave slope profile. As shown, the curvature of the arc is controlled via MCO, which is a commonly used term in surveying to define circular arcs. The single parameter MCO is the distance between Points 5 and 6 in Fig. 2b. Owning to its simplicity, MCO has been well accepted in projects which require construction of circular arcs (e.g., railroad curves).

It is desired to obtain the coordinates of any point along a concave profile as a function of $\mathrm{MCO}$, the average slope inclination, $\beta$, and the slope height, $H$. It is noted that $\beta$ is defined as the orientation of a straight line connecting the toe (Point 1 in Fig. 2a) to the crest (Point 3 in Fig. 2a). For the given slope geometry, the Long-Chord (LC) is known, which is defined as the straight line between Points 1 and 3 (i.e., the length of the equivalent planar slope profile). According to Fig. 2b, MCO and LC can be defined as:

$M C O=R_{C}\left(1-\cos \left(\frac{I}{2}\right)\right)$

$L C=\frac{H}{\sin \beta}=2 R_{C} \sin \left(\frac{I}{2}\right)$

where $R_{c}$ and $\mathrm{I}$ are the arc radius and the arc angle, respectively. Solving for $R_{c}$ in Eq. 1 and substituting it into Eq. 2:

$\frac{H}{\sin \beta}=\frac{2 M C O}{1-\cos \left(\frac{I}{2}\right)} \sin \left(\frac{I}{2}\right)$

and:

$I=4 \tan ^{-1}\left(\frac{2 M C O \sin \beta}{H}\right)$

By substituting Eq. 4 into Eq. 1 and using trigonometric relations, $R_{c}$ can be determined as: 
$R_{C}=\frac{H^{2}}{8 M C O}\left(1+\cot ^{2} \beta\right)+\frac{M C O}{2}$

The center of the circular arc $\left(x_{c c}, y_{c c}\right)$ is located on the bisector of LC and can be defined as:

$x_{c c}=-R_{c} \cos \zeta$

$y_{c c}=R_{c} \sin \zeta$

where $\zeta$ is the angle of rotation from the toe to the center of the circular arc with respect to the horizontal (see Fig. 2b):

$\zeta=\frac{\pi+I}{2}-\beta$

where $0 \leq \beta \leq \frac{\pi}{2}$. Substituting Eqs. 3, 4, 5 and 7 into Eq. 6 will yield the coordinates of the circular arc as function of $\mathrm{H}, \mathrm{MCO}$, and $\beta$ :

$x_{c c}=\left(\frac{H^{2}}{8 M C O}\left(1+\cot ^{2} \beta\right)+\frac{M C O}{2}\right) \sin \left(2 \tan ^{-1}\left(\frac{2 M C O \sin \beta}{H}\right)-\beta\right)$

$y_{c c}=\left(\frac{H^{2}}{8 M C O}\left(1+\cot ^{2} \beta\right)+\frac{M C O}{2}\right) \cos \left(2 \tan ^{-1}\left(\frac{2 M C O \sin \beta}{H}\right)-\beta\right)$

The $y$-coordinate of any point on the circular arc can be determined using the equation of a circle defined as:

$y=y_{c c}-\sqrt{R_{c}{ }^{2}-\left(x-x_{c c}\right)^{2}}$

where $R_{c}, x_{c c}$, and $y_{c c}$ can be calculated using Eqs. 5 and 8, respectively. For a given $\beta$ and $\mathrm{H}$, one can find the optimal slope profile by varying MCO. The lower limit of MCO is zero, representing a planar profile. The upper limit of MCO needs to be selected by taking into account the physical admissibility of the final profile. For steep slopes, the most stable slope profile tends to generate a negative slope at the crest, an overhanging cliff (e.g., Utili and Nova 
2007). However, a negative slope at the crest implies the potential development of tension cracks and therefore, is not considered as permissible in the optimization process. To exclude negative slopes at the crest, a physical constraint is defined to limit the maximum feasible concavity to the case with a vertical tangent at the crest. Subsequently, the range of MCO can be defined as follows:

$0 \leq M C O \leq \frac{1}{2}\left(\sqrt{\left((H-2)^{2}+(H \cot \beta)^{2}\right)(\sec \beta)^{2}}-\sqrt{((H-2) \sec \beta)^{2}}\right)$

\section{Slope Stability Formulation}

The MCO-based formulation of the concave slope profile, which was introduced in the previous section, is incorporated into the LE log spiral slope stability formulation (Fig. 2a). The LE formulation for the body defined by the log spiral surface explicitly satisfies the moment equilibrium condition and implicitly satisfies the force equilibrium equations without resorting to any assumptions (e.g., Leshchinsky and Mullett 1988). The log spiral procedure is recognized as "theoretically the best procedure for analysis of homogeneous slopes" (Duncan and Wright 2005). The log spiral mechanism in the context of limit state analysis has been successfully used for various homogeneous soil slope stability problems including partially saturated soils, seepage flow, surcharge loads, seismicity, and complex geometry (e.g., Leshchinsky and Mullett 1988; Leshchinsky and San 1994; Vahedifard et al., 2012; 2013; 2015; 2016c).

The moment equilibrium equation around the pole of the log spiral $\left(x_{C L}, y_{C L}\right)$ can be written as (Fig. 2a):

$$
W\left(1-k_{v}\right)\left(x_{C G}-x_{C L}\right)+k_{h} W\left(y_{C L}-y_{C G}\right)+\mathrm{c} \int\left(y_{F}-y_{C L}\right) d x-\mathrm{c} \int\left(x_{F}-x_{C L}\right) d y=0
$$

where $\mathrm{W}$ is the weight of the failure mass, $c$ is the design cohesion, $k_{h}$ is the horizontal seismic coefficient, and $k_{v}$ is the vertical seismic coefficient (upward positive). As shown in Fig. 2a, $\left(x_{C G}, y_{C G}\right)$ are the coordinates of the center of gravity of the failure mass, and $x_{F}$ and $y_{F}$ are the coordinates of any point along the slip surface. An assumed log spiral failure surface can be 
fully defined using $\left(x_{C G}, y_{C G}\right)$ and log spiral constant, $\mathrm{A}_{1}$. The log spiral radius $\left(R_{L}\right)$ at any point is defined as $R_{L}=A_{1} e^{-\psi \delta}$, where $\psi=\tan \phi$ (where $\phi$ is the design internal angle of friction) and $\delta$ is the angle of rotation from the pole of log spiral to the point. Explicit form of each contributing moment term is presented in Appendix $A$.

It is noted that current LE-based log spiral slope stability formulations are derived for planar profiles. Concavity of the slope affects $W$, and any increases in MCO will decrease $W$ and the associated moment terms in the moment equilibrium equation. In the current study, the log spiral moment equilibrium equation is modified to account for concave profiles. For each MCO, the moment due to the confined area between the planar profile (i.e., straight line connecting Points 1 (p1) and 3 (p3) in Fig. 2a) and concave profile (i.e., curve connecting Points 1 and 3 in Fig. 2a) is calculated and subtracted from the pertinent moment terms. The terms used to calculate the moment of the subtracted area due to concavity are presented in Appendix A.

The formulation for the log spiral failure surface in this work is applicable to homogeneous slopes. However, it should be noted that the proposed approach for finding the optimal slope profile can be used along with rigorous LE methods (e.g., Spencer, MorgensternPrice) or numerical methods to deal with more complex problems (e.g., non-homogeneous slopes). Since the log spiral formulation is rigorous and does not require any static assumption, the current formulation creates a benchmark for slope stability methods that involve static assumptions while being capable of dealing with complex slope problems.

\section{Solution Procedure}

The solution procedure starts with finding $\mathrm{N}$ for a planar profile (i.e., $\mathrm{MCO}=0$ ). For given input parameters and MCO, one can follow Taylor's (1937) classic slope stability design charts to find the stability number, $\mathrm{N}$, which is the normalized design cohesion (i.e., $N=\frac{c}{\gamma H}$ ), satisfying 
the LE state. Similar stability charts are used by Utili and Nova (2007) for concave slopes. After finding $\mathrm{N}$ for $\mathrm{MCO}=0, \mathrm{MCO}$ is then incrementally increased and the $\mathrm{N}$ value corresponding to each MCO is calculated and recorded. Reduction in the slope volume per unit length of the slope $(\triangle \mathrm{A})$ for each $\mathrm{MCO}$ can be calculated by finding the area confined between the tested concave profile and the planar profile.

Another parameter of interest recorded for each $\mathrm{MCO}$ is the height above the toe where the critical failure surface exits $\left(Y_{e}\right)$ (Point 4 in Fig. 2a). For homogeneous slopes with planar profiles, the critical failure surface passes through the toe (referred to as toe failure) except for cases with low $\phi$ (e.g., <20 degrees) and low $\beta$ values where the surface emerges away from the toe, forming deep-seated failures. Such deep-seated failures are not considered in this work. Consequently, when $\mathrm{MCO}=0, \mathrm{Y}_{\mathrm{e}}=0$. However, in concave slopes the critical failure surface may emerge above the toe (i.e., $Y_{e}>0$ ) and such possibility needs to be considered (Utili and Nova 2007; Jeldes et al. 2014). The later failure is referred to as face failure. For each MCO, in order to capture the most critical failure surface (i.e., highest N), a given circular profile must first be divided into $n$ equally-spaced distinct points along its height. Further, each point along the slope profile is treated as a potential exit point for the failure surface. Subsequently, the local stability number $\left(\mathrm{N}_{\mathrm{i}}\right)$ corresponding to each potential exit point is determined and recorded. The largest $N_{i}$ and its corresponding $Y_{e}$ are taken as the global $N$ and $Y_{e}$ for that MCO. The same procedure is then repeated for each MCO that is examined in the optimization search.

Figs. 3 and 4 show the results for two slopes of 70 and 45 degrees, respectively. It is noted all the results are presented in normalized form. It is noted that in these figures $y$ and MCO values are normalized by $\mathrm{H}$, and $\triangle \mathrm{A}$ values are normalized by $\mathrm{H}^{2}$. Both figures pertain to a slope with $\phi=30$ degrees, a horizontal backslope, and no seismicity. For $\beta=70$ degrees, Fig. 3a shows three slope profiles and their corresponding failure surfaces. In Fig. 3a, Case 1 shows 
the results for a planar profile (i.e., $\mathrm{MCO} / \mathrm{H}=0$ ). This Case results in the least stable (highest $\mathrm{N}$ value) and no reduction in volume $\left(\Delta \mathrm{A} / \mathrm{H}^{2}=0\right)$ as shown in Fig. 3b. Case 3 in Fig. 3a represents the results for $\mathrm{MCO} / \mathrm{H}=0.10$, which is the largest allowed concavity for the given geometry (i.e., profile with a vertical tangent at the crest based on Eq. 10). As can be seen, Case 3 results in the lowest value for $N$ and highest $\Delta A / H^{2}$. For Case 2 in Fig. 3a, the slope face lies between Cases 1 and 3. As demonstrated in Fig. 3a, $Y_{e} / H=0$ for all three cases, which indicates that toe failure is the most critical failure mode for this slope regardless of the MCO value. Fig. $3 b$ illustrates the relationship between $N$ and $M C O / H$, as well as $\Delta A$ and $M C O / H$, for the same slope. As shown, $\mathrm{N}$ monotonically decreases as $\mathrm{MCO}$ increases, ranging from $\mathrm{N}=0.087$ for $\mathrm{MCO} / \mathrm{H}=0$ to $\mathrm{N}=0.074$ for $\mathrm{MCO} / \mathrm{H}=0.1$. Furthermore, Case 2 represents the intersection of curves for $\mathrm{N}$ and $\Delta \mathrm{A}$. Such Case can be taken as the optimal point when stability and slope volume reduction criteria are equally weighted and need to be simultaneously considered for defining the optimal slope profile.

The results presented in Fig. 4 are indicative of a flatter slope with $\beta=45$ degrees and the other input parameters identical to those in the previous example. The trends represented are different than those observed in Fig. 3 for $\beta=70$ degrees. As shown in Fig. 4a, as MCO increases, the mode of failure changes from toe failure (Case 1 in Fig. 4b) to face failure (Case 3 in Fig. 4b). The results in Fig. 4b are presented for MCO/H ranging between 0 (planar slope) and 0.30 (largest allowed concavity based on Eq. 10), with $\beta=45$ degrees. Unlike the steep slope ( $\beta=70$ degrees), Fig. $4 \mathrm{~b}$ shows that $\mathrm{N}$ does not exhibit a monotonic trend with MCO. As shown, $\mathrm{N}$ slightly decreases as $\mathrm{MCO}$ increases, reaching a minimum of $\mathrm{N}=0.024$ at $\mathrm{MCO} / \mathrm{H}=$ 0.06 (Case 2 in Fig. 4b). Beyond Case 2 in Fig. 4b, $\mathrm{N}$ and $\mathrm{MCO} / \mathrm{H}$ increase up to $\mathrm{N}=0.048$ and $\mathrm{MCO} / \mathrm{H}=0.3$. The alteration in the trend is the result of changes in the mode of failure from toe failure to face failure occurred due to the change in the MCO. 
Figs. 3 and 4 show that the relationship between $\mathrm{N}$ and $\mathrm{MCO} / \mathrm{H}$ can have different trends, depending upon $\beta$. As shown for Case 3 in Fig. 3, the largest allowed concavity results in the most stable configuration for the steep slope. In such case, it is not difficult to select the optimal $\mathrm{MCO}$, for this value provides both the lowest $\mathrm{N}$ and the largest $\Delta \mathrm{A}$. However, a different trend was observed for flatter slopes (e.g., Fig. 4). Depending upon economical aspects and technical needs of the project, the value of MCO can be selected based on the lowest N (e.g., Point 3 in Fig. $3 b$ and Point 2 in Fig. 4b) and/or largest $\Delta A$ (e.g., MCO corresponding to Point 3 in Fig. 3b), or the point where the curves for $\mathrm{N}$ and $\Delta \mathrm{A}$ intersect (e.g., Point 2 in Fig. 3b). For example, for a cut slope, higher $\Delta \mathrm{A}$ means larger volume of soil needs to be excavated which will cost more. However, for a fill slope with stabilized soil, higher $\Delta \mathrm{A}$ will reduce the volume of soil to be placed which can be cost effective.

\section{Parametric Study and Stability Charts}

For a given slope angle, MCO is the only parameter for the optimization search. The results shown in this section are plotted for the MCO yielding the most stable configuration for each slope. That is, in these figures the optimum MCO is shown which represents the slope with the lowest $\mathrm{N}$. The results in Fig. 5 demonstrate the impact of $\phi$ and $\beta$ on $\mathrm{N}, \mathrm{MCO} / \mathrm{H}, \mathrm{Y}_{\mathrm{e}} / \mathrm{H}$, relative decrease in $\mathrm{N}$, and reduction in $\Delta \mathrm{A} / \mathrm{H}^{2}$.

Fig. 5a depicts the relationship between $N$ and $\beta$ for both planar and concave and profiles at various $\phi$ values. For a planar slope, $\mathrm{N}$ decreases somewhat linearly within a decrease in $\beta$. Likewise, for a concave slope, $\mathrm{N}$ decreases more nonlinearly with a decrease in $\beta$. The trends in Fig. 5a indicate that the concave profile at each $\phi$ value is more stable than the alternative planar profile. The stability numbers for the concave profile are identical to those for the planar profile for $\beta=90$ degrees and $\beta=\phi$. This is since no concavity was feasible (MCO = 0 ) for vertical slopes ( $\beta=90$ degrees). For flat slopes where $\beta$ approaches $\phi$, the stability 
number tends to reach zero. It is noted that the results shown in Fig. 5a are almost identical to those presented in Fig. 6 in Utili and Nova (2007) using the upper bound theory of LA method. This theory is higher in its hierarchy in mechanics when compared to LE.

Fig. $5 b$ illustrates the relationship between the optimum values for MCO and corresponding $\beta$ values at various $\phi$. For a given $\phi$, the MCO reaches a global maximum (i.e., referred to from here on out as the turning angle) when $\beta$ is approximately equal to the average of $\beta=90$ degrees and $\beta=\phi$, plus 5 degrees. For example, for $\phi=30$ degrees, the MCO reaches a global maximum when $\beta$ is approximately 65 degrees $(=[90+30] / 2+5)$. For $\beta$ values smaller than the turning angle, the optimum value for MCO decreases significantly up to $\beta=\phi$ (i.e., $\mathrm{MCO} / \mathrm{H}=0$ ). This indicates that for each $\phi$ the mode of failure changes from a toe failure to a face failure for slope angles smaller than the turning angle. As a result, a lower value of $\beta$ results in lower concavity. Further, for slopes smaller than the turning angle the $\mathrm{MCO} / \mathrm{H}$ becomes larger with decreasing $\phi$. This is because as $\phi$ increases, lower $\mathrm{c}$ is required to reach the LE state. Larger concavity is feasible when higher cohesion (or equivalent retention system) presents. As cohesion increases, all segments comprising the concave slope profile can become steeper than $\phi$.

In relation to the turning angle shown in Fig. 5b, Fig. 5c depicts the variation in normalized $Y_{e}$ with varying values of $\beta$ and $\phi$. As can be seen, a higher $\phi$ value results in a higher $Y_{\mathrm{e}}$. Moreover, the mode of failure changes from toe failure to face failure at turning angles of $\beta=62,68,72,76$ degrees for $\phi=20,30,40$ and $\phi=50$ degrees, respectively. In addition, Fig. $5 c$ suggests that for a given $\phi$ value, $Y_{e}$ decreases with an increase in $\beta$, up to the turning point. Beyond this point, $\mathrm{Y}_{\mathrm{e}}$ instantaneously drops to zero (i.e., toe failure).

Fig. $5 \mathrm{~d}$ is indicative of the decrease in $\mathrm{N}$ and corresponding $\Delta \mathrm{A} / \mathrm{H}^{2}$ relative to the same slope with planar profile. As shown, $\mathrm{A} / \mathrm{H}^{2}$ decreases with an increase in $\phi$. Conversely, the 
relative decrease in $\mathrm{N}$ increases with an increase in $\phi$. For all values of $\beta$, the highest $\Delta \mathrm{A} / \mathrm{H}^{2}$ and lowest relative reduction in $\mathrm{N}$ are observed at $\phi=20$ degrees, while the lowest $\Delta \mathrm{A} / \mathrm{H}^{2}$ and highest relative reduction in $\mathrm{N}$ are seen at $\phi=50$ degrees.

In summary, steep slopes ( $\beta>60$ degrees) are typically governed by toe failure (Fig. 5c). In the case of toe failure for $\beta>60$ degrees, the maximum concavity leads to an optimum slope design and yields the most stable configuration (i.e., lowest N). However, for milder slopes ( $\beta<60$ degrees), depending on the concavity, the failure varies between face failure and toe failure. In the case of face failure for $\beta<60$ degrees, $N$ increases with an increase in concavity. Conversely, in the case of toe failure at $\beta<60$ degrees, $N$ decreases with an increase in concavity. The reported results show that in almost all cases the critical $\mathrm{N}$ values belong to the slip surfaces going through or close to the toe of the slope. It is noted that while the curved slope is steeper in its upper portion, its 'height' is much less than the height of the entire curved slope. In c- $\phi$ slopes not only the slope steepness is playing a role but also its height. The current analysis considers both parameters to yield the critical $\mathrm{N}$.

\section{Effect of Backslope}

The effect of backslope on the design of concave slopes is demonstrated in Fig. 6. More specifically, the results are demonstrated for three different backslopes (i.e., $1 \mathrm{~V}: 10 \mathrm{H}, 1 \mathrm{~V}: 3 \mathrm{H}$, $1 \mathrm{~V}: 2 \mathrm{H})$ at $\phi=30$ degrees. The results presented in Fig. 6a depict the variation of $\mathrm{N}$ with respect to $\beta$ for the three backslopes. As it can be seen, an increase in the backslope leads to a slight increase in N. In Fig. 6, the results are shown for the MCO yielding the most stable configuration (i.e., lowest N).

Fig. $6 b$ represents the effect of backslope on the relationship between $Y_{e}$ and $\beta$ for $\phi=$ 30 degrees. As illustrated for each backslope, the failure mode changes from toe failure to face failure at $\beta=68$ degrees. Such behavior shows that the change of failure mode is unassociated with the type of backslope. However, an increase in the backslope is associated with a 
considerable decrease in $\mathrm{Y}_{\mathrm{e}}$, where the largest backslope of $1 \mathrm{~V}: 2 \mathrm{H}$ results in the smallest value for $Y_{e}$. In regard to the face failure $\left(\beta<68\right.$ degrees), as $\beta$ increases, the decrease in $Y_{e}$ is not as pronounced for higher backslopes. Specifically, for the backslope $1 \mathrm{~V}: 10 \mathrm{H}, \mathrm{Y}_{\mathrm{e}}$ for $\beta \leq 66$ degrees decreases approximately $3 \%$. Furthermore, $\mathrm{Y}_{\mathrm{e}}$ for $1 \mathrm{~V}: 3 \mathrm{H}$ and $1 \mathrm{~V}: 2 \mathrm{H}$, decreases $2 \%$ and $1 \%$, respectively, as $\beta$ varies from $\phi$ to 66 degrees.

Fig. $6 \mathrm{c}$ illustrates the relative decrease of $\mathrm{N}$ with respect to $\beta$ for $\phi=30$ degrees. As demonstrated, the relative decreases in $\mathrm{N}$ diminishes with an increase in the backslope. As previously noted, the merit of the concave slope is that the $\mathrm{N}$ value can be less than that for planar slopes at a specific value for $\beta$. However, as it is illustrated in Fig. $6 c$, an increase in the backslope leads to decrease in the performance of the concave slope. Hence, the $\mathrm{N}$ value for the optimum slope profile begins to converge to that for a planar profile.

In summary, the $\mathrm{N}$ value increases as the backslope increases, and as the backslope increases, the relative decrease of $\mathrm{N}$ decreases. On the other hand, $\mathrm{Y}_{\mathrm{e}}$ decreases for higher values of backslope. However, it has been demonstrated that the turning angle is independent of the effect of backslope.

\section{Effect of Seismicity}

The effect of seismicity is an important parameter in the design of concaves slopes which has not been included in the previous studies of concave slopes. A pseudostatic analysis is performed to determine the effect of seismicity on the optimum profile for concave slopes at different values of $k_{h}$. The pseudostatic results are presented for $k_{v}=0$. However, both $k_{h}$ and $k_{v}$ are included in the proposed formulation.

The results in Fig. 7 demonstrate the impact of $\phi, \beta$, and $k_{h}$ on $N, M C O / H, Y_{e} / H$, and the relative decrease in $\mathrm{N}$. For each $\beta$, the results are shown for the MCO yielding the lowest $\mathrm{N}$. Specifically, Fig. 7a demonstrates the effect of $k_{h}$ on $N$ for various values of $\beta$ at $\phi=30$ and 40 
degrees. For $\beta$ greater than $\phi$ and less than 90 degrees, the difference between $\mathrm{N}$ for concave and planar slopes increases as $k_{h}$ increases. Similar to the trend shown in the results for static loading, stability numbers of concave and planar profiles under seismic conditions become very close together for slopes with very high $\beta$. For these near vertical slopes, all concave profiles reduce to the planar profile which is due to the constraint introduced to keep the crest unchanged.

Fig. $7 \mathrm{~b}$ illustrates the impact of seismicity on MCO for the range of $\beta$ between 30 and 90 degrees. As shown, the turning angle decreases with an increases in $k_{h}$ for a given $\phi$. As expected, more concavity is required in order to form a stable slope during severe earthquakes. Also, as $k_{h}$ increases, the turning angle associated with the change of failure mode decreases. In Fig. 7c, the impact of $k_{h}$ on $Y_{e}$ is demonstrated for various values of $\beta$ and $\phi$. It is apparent that an increase in $k_{h}$ leads to decreases in $Y_{e}$ and the turning angle. In addition, toe failure under seismic conditions, in comparison to static conditions, covers a wider range of slopes.

Fig. 7d illustrates the relationship between the relative reduction of $N$ and $\beta$ for different $k_{h}$ and $\phi$ values. The relative reduction of $N$ continuously increases from $\beta=90$ degrees up to the turning angle for a given $k_{h}$. Regardless of $\phi$, the reduction of $N$ decreases as $k_{h}$ increases. In addition, for lower values of $k_{h}$, the maximum reduction of $N$ occurs at $\beta=\phi$. However, by increasing $\mathrm{k}_{\mathrm{h}}$, the maximum reduction of $\mathrm{N}$ shifts to the turning angle. In comparison with static conditions (Fig. 5d), the relative reduction of $\mathrm{N}$ is higher in seismic conditions. In other words, the performance of concave slopes for seismic conditions is better than the performance for static conditions. Using concave profiles will reduce the sliding mass and subsequently, its inertia. Under seismic loading, a smaller inertia will lead to a lower destabilization. This could lead to a significant improvement of concave slopes over planar slopes. Overall, the difference in $\mathrm{N}$ between planar and concave profiles for seismic conditions increases for increasing values 
of $k_{h}$. Moreover, the turning angle for seismic conditions decreases with an increases in $k_{h}$, and toe failure dominates for a wider range of $\beta$.

\section{Comparisons with Limit Analysis with Discontinuity Layout Optimization}

The results from the proposed formulation are compared with those obtained from the computer program LimitState:GEO (2014). The program uses the Discontinuity Layout Optimization (DLO) (Smith and Gilbert 2007) linear programming procedure to produce a numerical rigorous upper-bound solution in LA, of plasticity. It automatically identifies, linearwise, the critical layout of slip-lines in a soil mass that is at a limit state. Use of the DLO algorithm eliminates the need for assuming a critical failure mechanism, a step that is required in most alternative LE analyses.

Since LimitState:GEO (referred to as LA-DLO hereafter) uses non-assumptive failure geometry in its formulation, a series of 12 LA-DLO models (6 planar and 6 concave models) were constructed as a comparison tool, comparing stability number and height of exit point (i.e., mode of failure) attained from the presented LE methodology, which assumes a log spiral slip surface, to LA-DLO, which does not. Different scenarios were simulated for both planar and optimal slopes including two slope angles ( $\beta=70$ or 45 degrees), two backslope angles $(\alpha=0$ or 26.6 degrees, which is $1 \mathrm{~V}: 2 \mathrm{H}$ backslope), and two horizontal seismic coefficients $\left(\mathrm{k}_{\mathrm{h}}=0\right.$ or 0.3). All models consisted of a slope with $\mathrm{H}=5 \mathrm{~m}, \gamma=20 \mathrm{kPa}, \phi=30$ degrees, $\mathrm{k}_{\mathrm{v}}=0$. For each case which was examined, the concave profile obtained from the proposed optimization method was incorporated into the LA-DLO model.

As shown in Table 1, good agreement is demonstrated upon comparison of $\mathrm{N}$ and $\mathrm{Y}_{\mathrm{e}}$ attained from the proposed LE formulation and LA-DLO. Of the 12 permutations in this parametric study (6 planar and 6 concave slopes), good agreement is demonstrated for all cases which were examined, including those with seismicity and inclined backfill. Fig. 8 provides 
a comparison of failure slip surfaces from the current study versus LA-DLO for two cases of $\beta=$ 70 and 45 degrees for $\phi=30$ degrees. As seen, the shape of failure surface and $Y_{e}$ from the proposed LE method for both cases are also in good agreement with the counterpart LA-DLO models.

\section{Conclusions}

A methodology was proposed to obtain the stability number and optimal profile of slopes with concave cross section. The slope profile was idealized as a circular arc and the curvature was controlled by a single variable, the Mid-Chord Offset (MCO). The proposed formulation for concave facing profile was incorporated into a limit equilibrium-based log spiral slope stability formulation. Parametric studies were performed for homogeneous slopes with various angles of friction and slope angles, and the effects of seismicity and backslope inclination were demonstrated. Stability number, MCO, and mode of failure for the most stable configuration (i.e., lowest stability number) under static and pseudostatic loading conditions were presented. Good agreement was demonstrated between the results from the proposed method against those attended from limit analysis with discontinuity layout optimization.

The results from the current study showed that concave profiles can improve the stability of slopes by over 20 percent. For steep slopes, the stability number versus MCO relationship was shown to be monotonic and the maximum admissible concavity (i.e., least slope volume) happened to yield the most stable configuration, For flatter slopes, however, the stability number showed a non-monotonic relationship with $\mathrm{MCO}$, initially decreasing as $\mathrm{MCO}$ increases and after reaching a peak point, starting to drop beyond a certain MCO. Depending upon the project requirements and economical aspects, the designer can choose the stability or the slope volume or a combination of both as the optimization target to find the desired MCO for each slope. 
The effects of backslope inclination was investigated and it was found that the optimal MCO and mode of failure are almost independent from backslope variation. The performance of concave profile decreases with respect to an increase in backslope. In the same manner, by increasing the backslope, the difference between the exit point of the failure surface and toe of the slope decreases.

The effect of seismicity was also considered in this study. It was shown that the concave shape of a slope can significantly decrease the stability number. In the presence of seismicity, MCO increases with an increase in the horizontal acceleration. This trend leads to dominance of toe failure over a wider range of slopes. The maximum performance of concave slopes is achieved at a lower range of seismic coefficients. However, in the case of higher seismic coefficients, the maximum performance of concave slopes occurs when the angle of the slope is equal to the angle of friction for a given soil which possesses some cohesion. Moreover, the exit point of the failure surface approaches the toe of the slope as the seismic coefficient increases.

The proposed methodology can be used in practice for various engineered slopes such as cut slopes, trenches, open mine excavations, and when cohesion and/or an equivalent support system can be used for long term design purposes (e.g., rock slopes, earth retaining systems, cemented/stabilized fill slopes). Moreover, the algorithm can be used along with rigorous slopes stability methods to deal with more complex problems than log spiral is adequate to represent, such as non-homogeneous slopes. Simplicity of the proposed procedure, as well as continuous advances in construction equipment and technology further facilitate widespread use of proposed concave profiles in various projects.

\section{References}

Duncan, J. M. and Wright, S. G. 2005. Soil Strength and Slope Stability, John Wiley \& Sons, 297 pps.

Gray, D. 2013. "Influence of Slope Morphology on the Stability of Earthen Slopes." GeoCongress 2013: pp. 1895-1904. doi: 10.1061/9780784412787.191 
Jeldes, I. A., Vence, N. E., and Drumm, E. C. 2013. "Approximate solution to the Sokolovskil concave slope at limiting equilibrium." Int. J. Geomech., 10.1061/(ASCE)GM.19435622.0000330, 04014049 .

Jeldes, I., Drumm, E., and Yoder, D. 2014. "Design of Stable Concave Slopes for Reduced Sediment Delivery." J. Geotech. Engrg., 10.1061/(ASCE)GT.1943-5606.0001211, 04014093.

Leshchinsky, D. and Mullett, T. 1988. "Stability of Vertical Corner Cuts," Proceedings of the 6th International Conference on Numerical Methods in Geomechanics, Innsbruck, Austria, April 1988, pp. 1249-1256.

Leshchinsky, D., and San, K. C. 1994. "Pseudostatic seismic stability of slopes: Design charts." J. Geotech. Eng., 120(9), 1514-1532.

Leshchinsky, D. and Tatsuoka, F. 2013. "Geosynthetic reinforced walls in the public sector: Performance, design, and redundancy", Geosynthetics Magazine, 31(3), 12-21.

LimitState:GEO. 2014. LimitState:GEO Manual Version 3.2b, LimitState Ltd, July 10, 2014 Edition.

Nishida, K., Tamano, T., Morimoto, H. and Shrestha, B. 2005. "Geotechnical characteristics of Japanese castle masonry wall and mechanical analysis for its preservation." Proc. 16th ICSMGE, Osaka, Japan, 2763-2767.

Rieke-Zapp, D. H., and Nearing, M. A. 2005. "Slope shape effects on erosion." Soil Sci. Soc. Am. J., 69(5), 1463-1471.

Schor, H. J., and Gray, D. H. 2007. Landforming: An environmental approach to hillside development, mine reclamation and watershed restoration, Wiley, Hoboken, NJ.

Smith, C., and Gilbert, M. 2007. "Application of discontinuity layout optimization to plane plasticity problems." Proc. of the Royal Society A: Mathematical, Physical and Engineering Sciences, 463(2086), 2461-2484.

SokolovskiĬ, V. V. 1960. Statics of soil media, Butterworths Scientific Publications, London.

Taylor, D. W. 1937. "Stability of earth slopes." J. Boston Society of Civ. Engrs., 24(3), 197-246.

Utili, S., and Nova, R. 2007. "On the optimal profile of a slope." Soils Found., 47(4), 717-729.

Vahedifard, F., Leshchinsky, B., Mortezaei, K., and Lu, N. 2015. "Active Earth Pressures for Unsaturated Retaining Structures." J. Geotech. Geoenviron. Eng., 10.1061/(ASCE)GT.1943-5606.0001356, 04015048.

Vahedifard, F., Leshchinsky, D., and Meehan, C. L. 2012. "Relationship between the seismic coefficient and the unfactored force of geosynthetic in reinforced earth structures." J. Geotech. Geoenviron. Eng., 128(10), 1209-1221.

Vahedifard, F., Leshchinsky, D., and Meehan, C. L. 2013. "Displacement-Based Internal Design of Geosynthetic-Reinforced Earth Structures Subjected to Seismic Loading Conditions." Géotechnique, 63(6), 451-462. 
Vahedifard, F., and Leshchinsky, B. A., Sehat, S., and Leshchinsky, D. 2014. "Impact of Cohesion on Seismic Design of Geosynthetic-Reinforced Earth Structures." J. Geotech. Geoenviron. Eng., 140(6), 04014016.

Vahedifard, F., Shahrokhabadi, S., and Leshchinsky, D. 2016a. "Geosynthetic-Reinforced Soil Structures with Concave Facing Profile." Geotextiles and Geomembranes, 10.1016/j.geotexmem.2016.01.004.

Vahedifard, F., Mortezaei, K., Leshchinsky, B. A., Leshchinsky, D., and Lu, N. 2016b. "Role of Suction Stress on Service State Behavior of Geosynthetic-Reinforced Soil Structures." Transportation Geotechnics, DOI: 10.1016/j.trgeo.2016.02.002.

Vahedifard, F., Leshchinsky, D., Mortezaei, K., and Lu, N. 2016c. "Effective Stress-based Limit Equilibrium Analysis for Homogeneous Unsaturated Slopes." Int. J. Geomech., 10.1061/(ASCE)GM.1943-5622.0000554 , D4016003. 


\section{Appendix A: Log Spiral Formulation}

The explicit form of each contributing moment term in Eq. 11 is shown in the following. The following equations are derived using normalized parameters in order to generalize the application of the proposed formulation. That is, lengths are normalized by $\mathrm{H}$ and stresses are normalized by $\gamma \mathrm{H}$, where $\gamma$ is the total unit weight of soil. The moment terms are derived based on the geometry of the log spiral surface shown in Fig. 2a.

The moment due to $W\left(1-k_{v}\right.$ ) (i.e., the weight of area 1-2-3 in Fig. 2a), is:

$$
\begin{aligned}
\left(1-k_{v}\right)\left(x_{C G}-\right. & \left.x_{C L}\right) \\
& =\int_{\beta_{1}}^{\beta_{2}}\left(1-\mathrm{k}_{\mathrm{v}}\right)\left(A_{1} \mathrm{e}^{-\psi \beta} \cos \beta\right. \\
& \left.-A_{1} \mathrm{e}^{-\psi \beta_{2}} \cos \beta_{2}\right)\left(A_{1} \mathrm{e}^{-\psi \beta} \sin \beta\right)\left(A_{1} \mathrm{e}^{-\psi \beta}\right)(\cos \beta-\psi \sin \beta) \mathrm{d} \beta \\
& -\frac{1}{2}\left(1-\mathrm{k}_{\mathrm{v}}\right) \tan \omega\left(\frac{1}{3} \tan \omega+A_{1} \mathrm{e}^{-\psi \beta_{1}} \sin \beta_{1}\right) \\
& -\left(1-\mathrm{k}_{\mathrm{v}}\right) \tan \omega\left(A_{1} \mathrm{e}^{-\psi \beta_{1}} \cos \beta_{1}-A_{1} \mathrm{e}^{-\psi \beta_{2}} \cos \beta_{2}\right. \\
& -1)\left(A_{1} \mathrm{e}^{-\psi \beta_{1}} \sin \beta_{1}+\frac{1}{2} \tan \omega\right) \\
& -\frac{1}{2}\left(1-\mathrm{k}_{\mathrm{v}}\right)\left(A_{1} \mathrm{e}^{-\psi \beta_{2}} \sin \beta_{2}-A_{1} \mathrm{e}^{-\psi \beta_{1}} \sin \beta_{1}-\tan \omega\right)\left(A_{1} \mathrm{e}^{-\psi \beta_{1}} \cos \beta_{1}\right. \\
& \left.-A_{1} \mathrm{e}^{-\psi \beta_{2}} \cos \beta_{2}-1\right)\left[A_{1} \mathrm{e}^{-\psi \beta_{1}} \sin \beta_{1}+\tan \omega\right. \\
+ & \left.\frac{1}{3}\left(A_{1} \mathrm{e}^{-\psi \beta_{2}} \sin \beta_{2}-A_{1} \mathrm{e}^{-\psi \beta_{1}} \sin \beta_{1}-\tan \omega\right)\right]
\end{aligned}
$$

The moment due to $k_{h} W\left(y_{C L}-y_{C G}\right)$ can be calculated by: 
$k_{h} W\left(y_{C L}-y_{C G}\right)$

$$
\begin{aligned}
& =\int_{\beta_{1}}^{\beta_{2}} \frac{1}{2} \mathrm{k}_{\mathrm{h}}\left(A_{1} \mathrm{e}^{-\psi \beta} \cos \beta+A_{1} \mathrm{e}^{-\psi \beta_{2}} \cos \beta_{2}\right)\left(A_{1} \mathrm{e}^{-\psi \beta} \cos \beta\right. \\
& \left.-A_{1} \mathrm{e}^{-\psi \beta_{2}} \cos \beta_{2}\right)\left(A_{1} \mathrm{e}^{-\psi \beta}\right)(\cos \beta-\psi \sin \beta) \mathrm{d} \beta \\
& -\frac{1}{2} \mathrm{k}_{\mathrm{h}} \tan \omega\left(A_{1} \mathrm{e}^{-\psi \beta_{1}} \cos \beta_{1}-\frac{2}{3}\right) \\
& -\mathrm{k}_{\mathrm{h}} \tan \omega\left(A_{1} \mathrm{e}^{-\psi \beta_{1}} \cos \beta_{1}-A_{1} \mathrm{e}^{-\psi \beta_{2}} \cos \beta_{2}-1\right)\left[A_{1} \mathrm{e}^{-\psi \beta_{2}} \cos \beta_{2}\right. \\
& \left.+\frac{1}{2}\left(A_{1} \mathrm{e}^{-\psi \beta_{1}} \cos \beta_{1}-A_{1} \mathrm{e}^{-\psi \beta_{2}} \cos \beta_{2}-1\right)\right] \\
& -\frac{1}{2} \mathrm{k}_{\mathrm{h}}\left(A_{1} \mathrm{e}^{-\psi \beta_{1}} \cos \beta_{1}-A_{1} \mathrm{e}^{-\psi \beta_{2}} \cos \beta_{2}-1\right)\left(A_{1} \mathrm{e}^{-\psi \beta_{2}} \sin \beta_{2}\right. \\
& \left.-A_{1} \mathrm{e}^{-\psi \beta_{1}} \sin \beta_{1}-\tan \omega\right)\left[A_{1} \mathrm{e}^{-\psi \beta_{2}} \cos \beta_{2}\right. \\
& \left.+\frac{1}{3}\left(A_{1} \mathrm{e}^{-\psi \beta_{1}} \cos \beta_{1}-A_{1} \mathrm{e}^{-\psi \beta_{2}} \cos \beta_{2}-1\right)\right]
\end{aligned}
$$

The moment due to the design cohesion is:

$$
\begin{aligned}
c \int\left(y_{F}-y_{C L}\right) d x & -c \int\left(x_{F}-x_{C L}\right) d y \\
& =c \int_{\beta_{1}}^{\beta_{2}}\left(-A_{1} \mathrm{e}^{-\psi \beta} \cos \beta\right) A_{1}\left(\mathrm{e}^{-\psi \beta} \cos \beta-\psi \mathrm{e}^{-\psi \beta} \sin \beta\right) \mathrm{d} \beta \\
& -c \int_{\beta_{1}}^{\beta_{2}}\left(A_{1} \mathrm{e}^{-\psi \beta} \sin \beta\right) A_{1}\left(\psi \mathrm{e}^{-\psi \beta} \cos \beta+\mathrm{e}^{-\psi \beta} \sin \beta\right) \mathrm{d} \beta
\end{aligned}
$$

For concave profiles and for each $M C O$, the moment due to the confined area between the planar profile (i.e., straight line connecting Points 1 (p1) and 3 (p3) in Fig. 2a) and concave profile (i.e., curve connecting Points 1 and 3 in Fig. 2a) is calculated and subtracted from the pertinent moment terms. The subtracted area due to concavity can be calculated as: 


$$
\Delta A=\int_{p 1}^{p 2} f(x) d x=\int_{p 1}^{p 2}\left(x \tan (\beta)-\left(y_{c c}-\sqrt{R_{c}{ }^{2}-\left(x-x_{c c}\right)^{2}}\right)\right) d x
$$

Subsequently, the moment arm for this confined area is determined by calculating the center of the geometric center (i.e., centroid) as:

$$
\begin{aligned}
& \bar{x}=\frac{1}{\Delta A} \int_{\Delta A} x_{c} d \Delta A=\frac{1}{\Delta A} \int_{p 1}^{p 2} x f(x) d x \\
& \bar{y}=\frac{1}{\Delta A} \int_{\Delta A} y_{c} d \Delta A=\frac{1}{\Delta A} \int_{p 1}^{p 2} y f(y) d y
\end{aligned}
$$




\section{List of Tables}

Table 1. Comparison of results from LE (proposed method) and LA-DLO simulations for $\phi=30^{\circ}$

\section{List of Figures}

Fig. 1. Example of a natural slope with concave profile, on US-101, north of Alsea Bay Bridge, Waldport, Oregon, USA.

Fig. 2. Slope geometry and notation used in the formulation: a) Notation; b) Detail of circular arc used in optimizing the slope profile.

Fig. 3. Results for $\phi=30^{\circ}, \beta=70^{\circ}$ : a) Slope profile and slip surface for different normalized midchord offset, $\mathrm{MCO} / \mathrm{H}$; b) Stability number, $\mathrm{N}$, and reduction in the slope volume per unit length of the slope, $\Delta \mathrm{A} / \mathrm{H}^{2}$, versus normalized mid-chord offset, $\mathrm{MCO} / \mathrm{H}$.

Fig. 4. Results for $\phi=30^{\circ}, \beta=45^{\circ}$ : a) Slope profile and slip surface for different normalized midchord offset, $\mathrm{MCO} / \mathrm{H} ; \mathrm{b}$ ) Stability number, $\mathrm{N}$, and reduction in the slope volume per unit length of the slope, $\Delta \mathrm{A} / \mathrm{H}^{2}$, versus normalized mid-chord offset, $\mathrm{MCO} / \mathrm{H}$.

Fig. 5. Stability charts for the base model (no seismicity, horizontal backslope): a) Comparison of stability number, $\mathrm{N}$, for the most stable concave profile and planar profile; b) Normalized mid-chord offset, MCO/H, versus slope angle; c) Normalized height of exit point of the slip surface, $Y_{e} / H$, versus slope angle; d) Improvement in stability and reduction in slope volume by using concave versus planar slope profile.

Fig. 6. Stability charts for inclined backslope: a) Stability number, N, for the most stable concave profile; b) Normalized height of exit point of the slip surface, $Y_{e} / H$, versus slope angle; $c$ ) Improvement in stability and reduction in slope volume by using concave versus planar slope profile.

Fig. 7. Stability charts for seismic condition: a) Stability number, N, for the most stable concave profile; b) Normalized mid-chord offset, $\mathrm{MCO} / \mathrm{H}$, versus slope angle; c) Normalized height of exit point of the slip surface, $Y_{e} / H$, versus slope angle; d) Improvement in stability by using concave versus planar slope profile.

Fig. 8. Comparison of critical slip surfaces from the current study versus upper-bound solution in limit analysis with discontinuity layout optimization for $\phi=30^{\circ}$ : a) $\beta=45^{\circ}$; b) $\beta=70^{\circ}$. 
Table 1. Comparison of results from LE (proposed method) and LA-DLO simulations for $\phi=30^{\circ}$

\begin{tabular}{|c|c|c|c|c|c|c|c|c|c|}
\hline \multicolumn{3}{|c|}{ Model Properties } & \multicolumn{2}{|c|}{$\begin{array}{l}\mathrm{N} \text { for planar } \\
\text { slope }\end{array}$} & \multicolumn{2}{|c|}{$\begin{array}{l}\mathrm{N} \text { for concave } \\
\text { slope }\end{array}$} & \multicolumn{2}{|c|}{$\begin{array}{l}\text { Yexit for concave } \\
\text { slope }(/ \mathrm{H})\end{array}$} & \multirow{2}{*}{$\begin{array}{c}\Delta \mathrm{A} \text { by using } \\
\text { concave slope } \\
\text { per unit length } \\
\left(/ \mathrm{H}^{2}\right)\end{array}$} \\
\hline$\beta\left(^{\circ}\right)$ & $\alpha\left(^{\circ}\right)$ & $\mathrm{k}_{\mathrm{h}}$ & LE & LA-DLO & LE & LA-DLO & LE & LA-DLO & \\
\hline 70 & 0 & 0 & 0.087 & 0.084 & 0.074 & 0.075 & 0.000 & 0.000 & 0.066 \\
\hline 70 & 26.56 & 0 & 0.093 & 0.089 & 0.085 & 0.085 & 0.000 & 0.000 & 0.066 \\
\hline 70 & 0 & 0.30 & 0.157 & 0.153 & 0.140 & 0.139 & 0.000 & 0.000 & 0.066 \\
\hline 45 & 0 & 0 & 0.028 & 0.027 & 0.024 & 0.025 & 0.118 & 0.084 & 0.058 \\
\hline 45 & 26.56 & 0 & 0.030 & 0.028 & 0.027 & 0.028 & 0.05 & 0.000 & 0.058 \\
\hline 45 & 0 & 0.30 & 0.089 & 0.086 & 0.077 & 0.082 & 0.078 & 0.000 & 0.122 \\
\hline
\end{tabular}




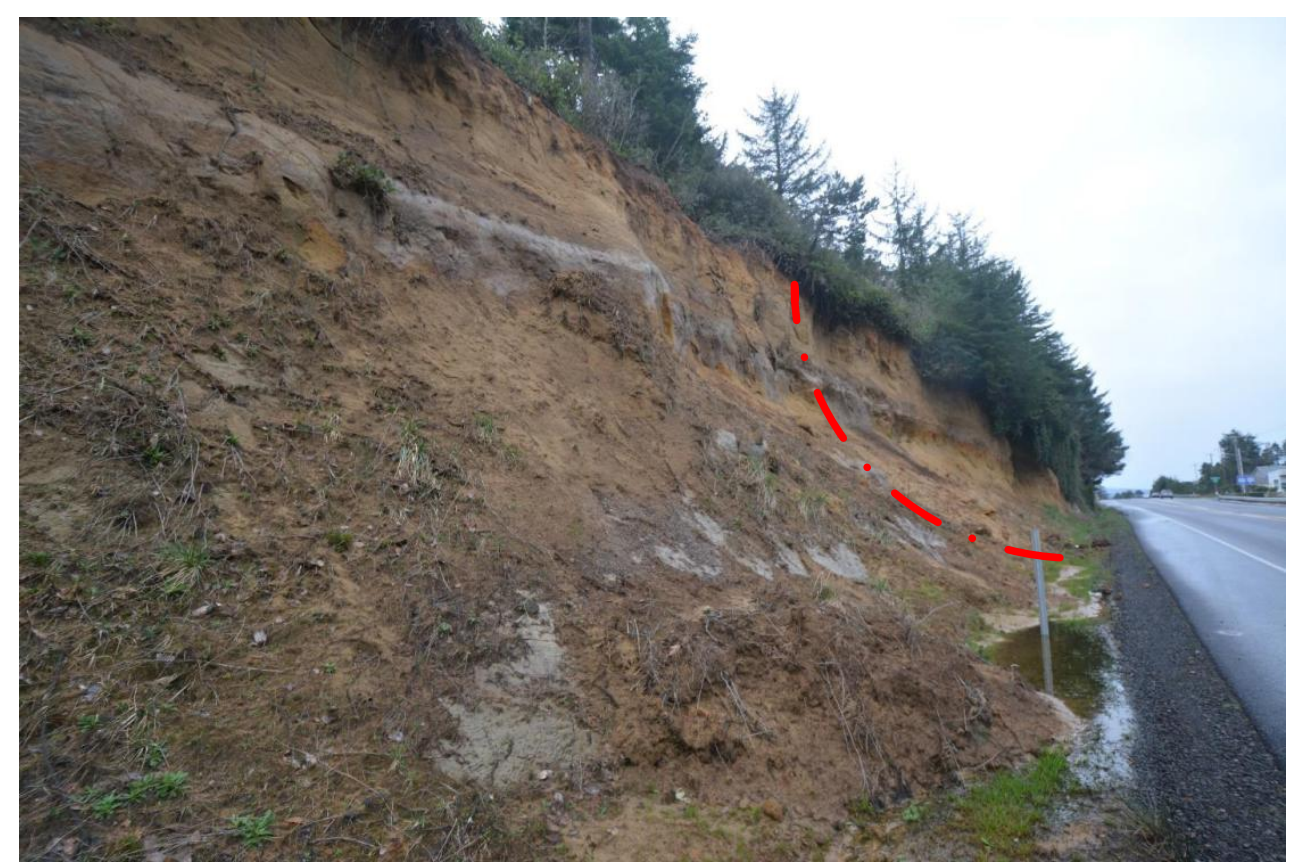

Fig. 1. Example of a natural slope with concave profile, on US-101, north of Alsea Bay Bridge, Waldport, Oregon, USA. 
(a)

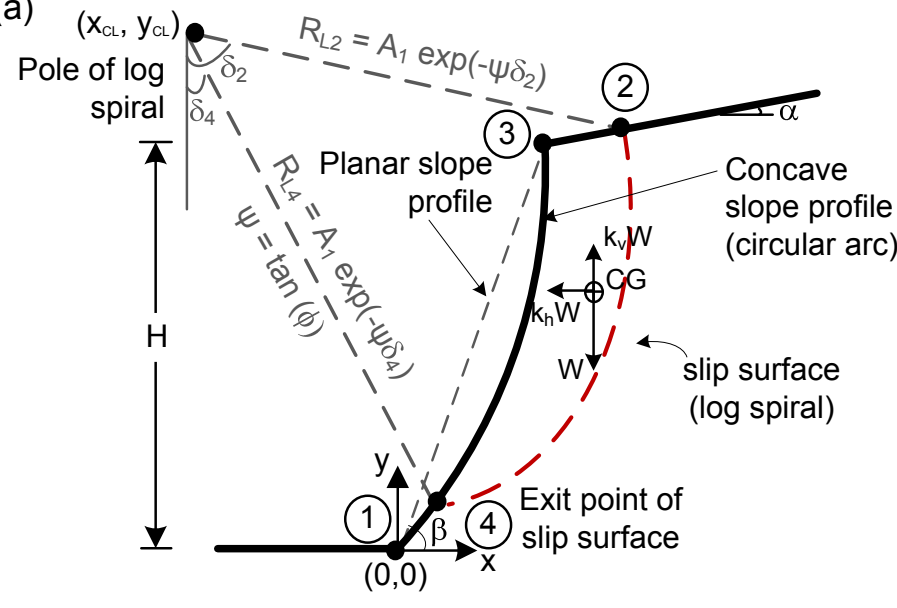

(b)

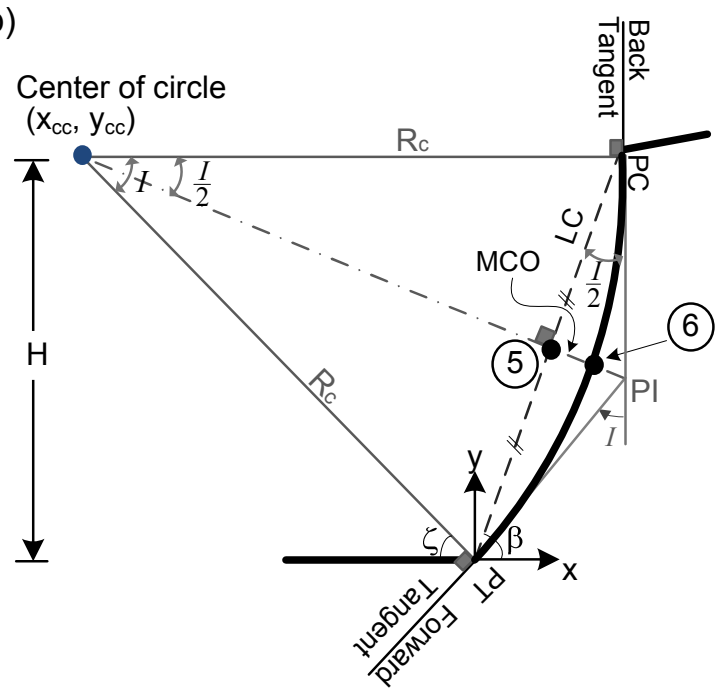

Fig. 2. Slope geometry and notation used in the formulation: a) Notation; b) Detail of circular arc used in optimizing the slope profile. 
(a)

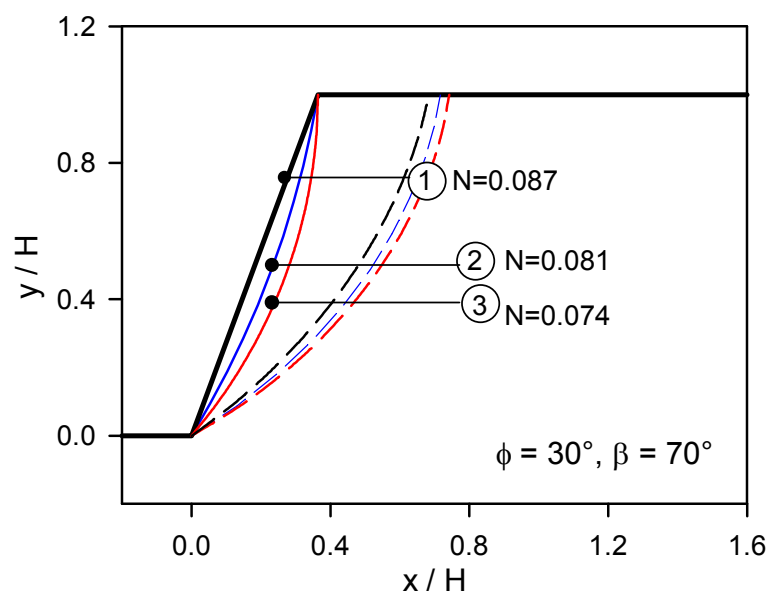

(b)

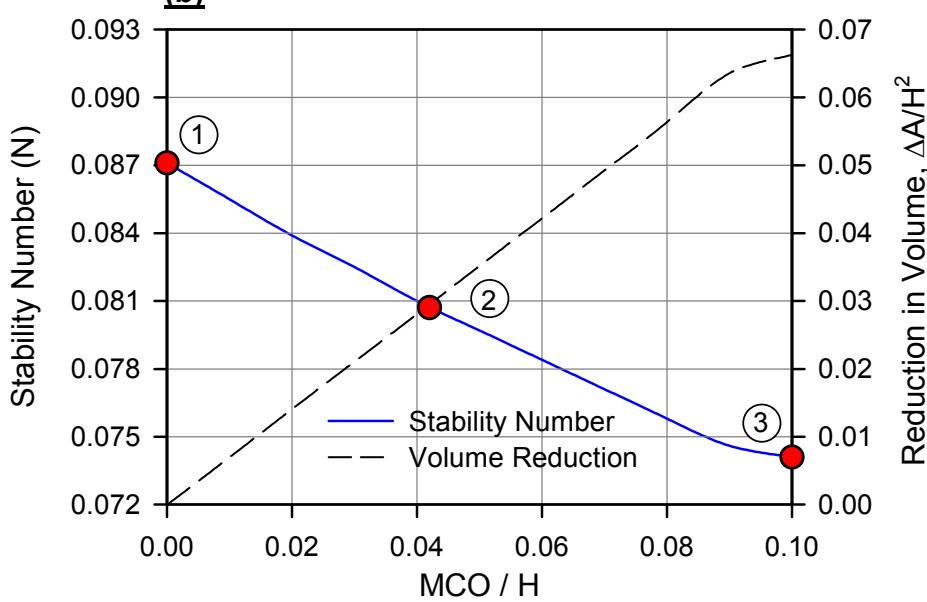

Fig. 3. Results for phi $=30$ deg, beta $=70$ deg: a) Slope profile and slip surface for different normalized mid-chord offset, $\mathrm{MCO} / \mathrm{H}$; b) Stability number, $\mathrm{N}$, and reduction in the slope volume per unit length of the slope, delta A/H2, versus normalized mid-chord offset, $\mathrm{MCO} / \mathrm{H}$. 
(a)

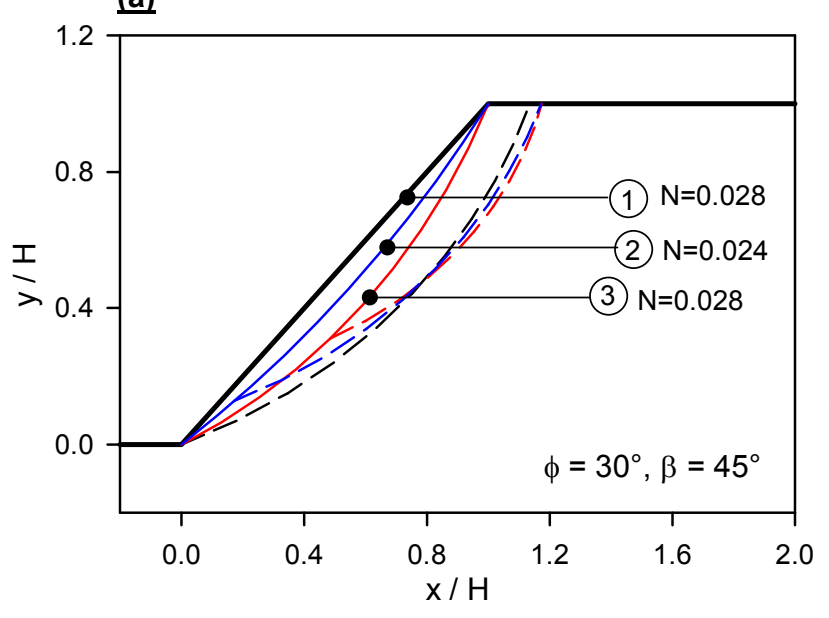

(b)

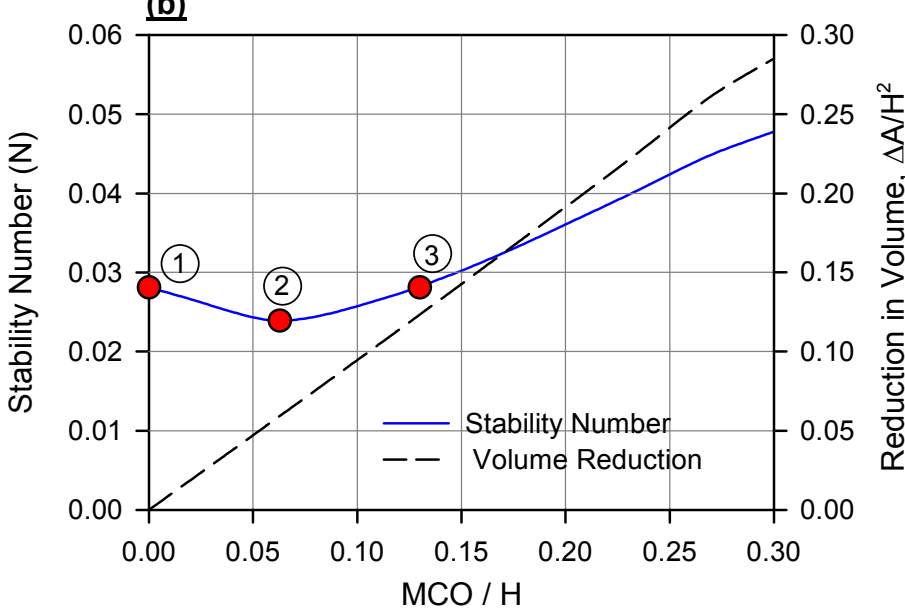

Fig. 4. Results for phi $=30$ deg, beta $=45$ deg: a) Slope profile and slip surface for different normalized mid-chord offset, $\mathrm{MCO} / \mathrm{H}$; b) Stability number, $\mathrm{N}$, and reduction in the slope volume per unit length of the slope, delta A/H2, versus normalized mid-chord offset, $\mathrm{MCO} / \mathrm{H}$. 

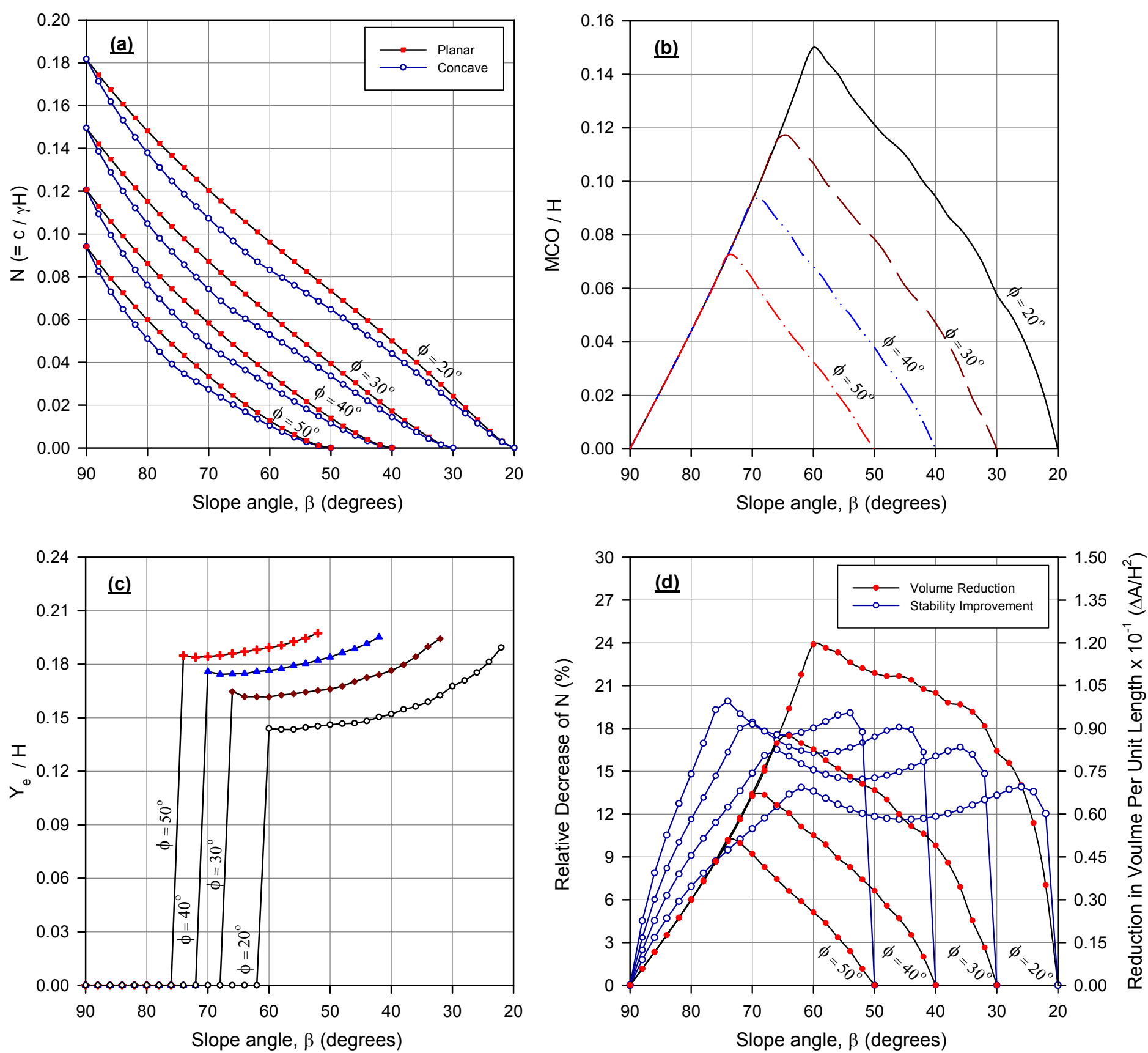

Fig. 5. Stability charts for the base model (no seismicity, horizontal backslope): a) Comparison of stability number, $N$, for the most stable concave profile and planar profile; b) Normalized mid-chord offset, MCO/H, versus slope angle; c) Normalized height of exit point of the slip surface, Ye/H, versus slope afgle/rid) Improvement in stability and reduction in slope volume by using concave versus planar slope profile. 

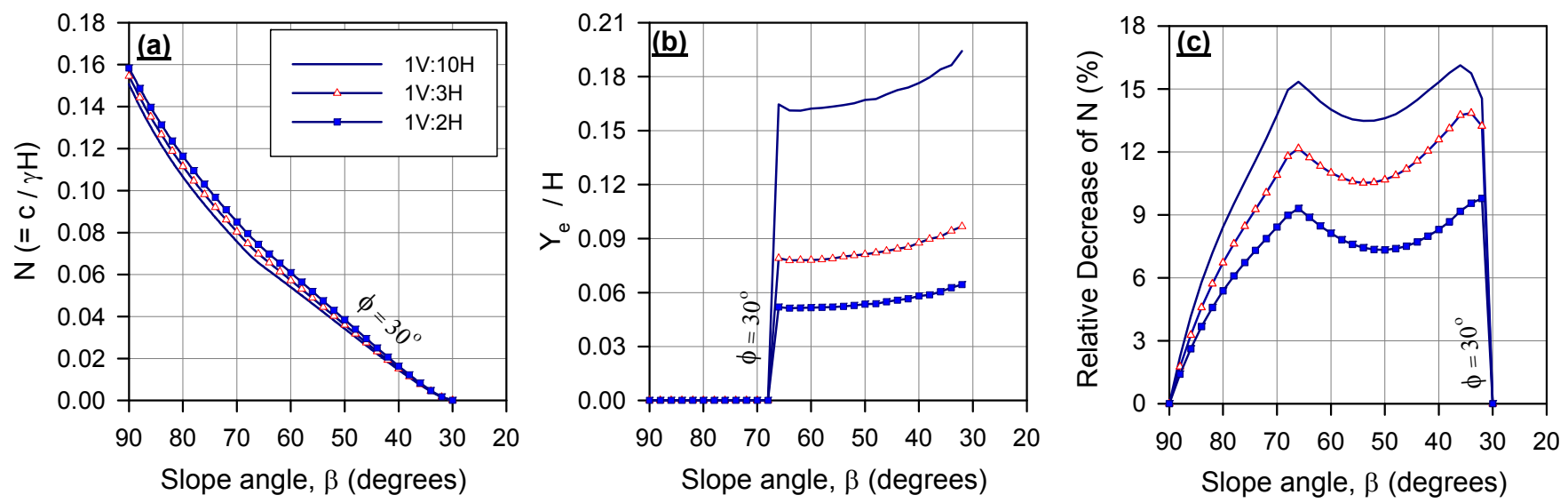

Fig. 6. Stability charts for inclined backslope: a) Stability number, $N$, for the most stable concave profile; b) Normalized height of exit point of the slip surface, Ye/H, versus slope angle; c) Improvement in stability and reduction in slope volume by using concave versus planar slope profile. 

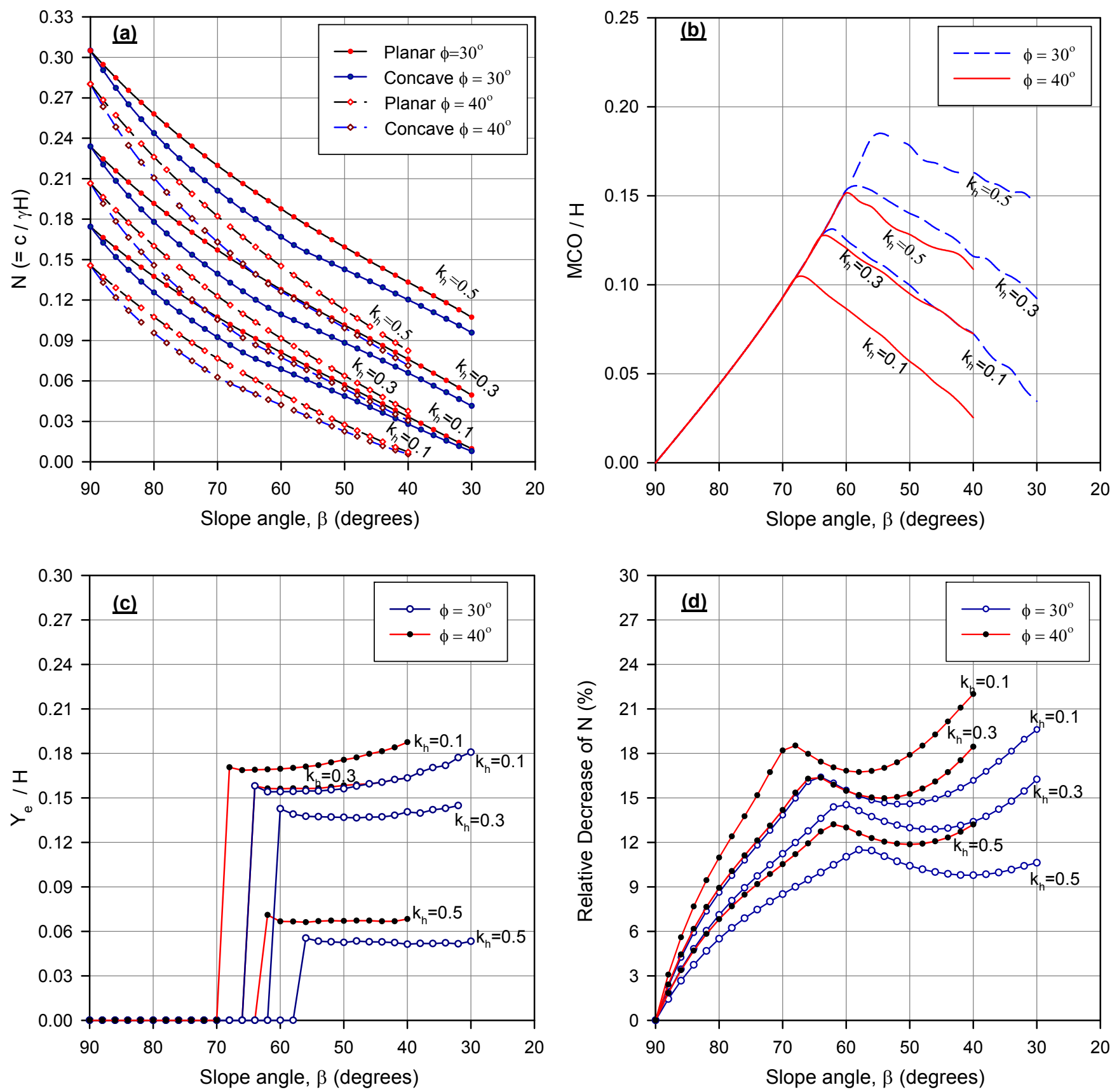

Fig. 7. Stability charts for seismic condition: a) Stability number, $N$, for the most stable concave profile; b) Normalized mid-chord offset, MCO/H, versus slope angle; c) Normalized height of exit point of the slip surface, Ye/H, versus slope angle; d) Improvement in stability by using concave versus planar slope profile. 
(a)

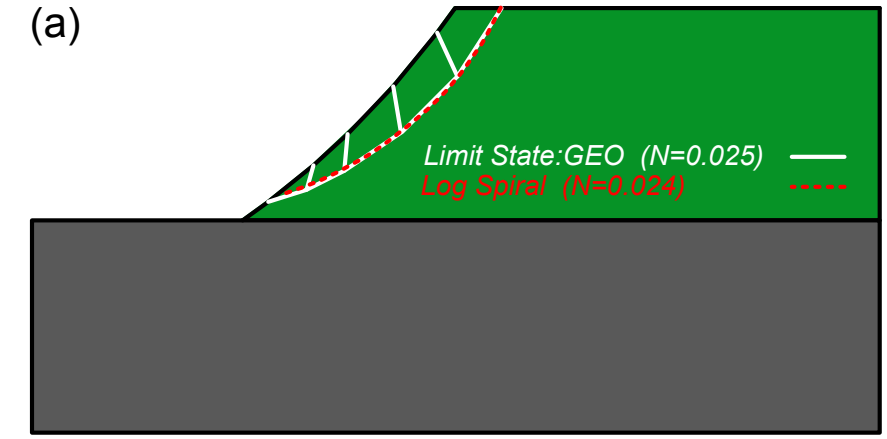

(b)

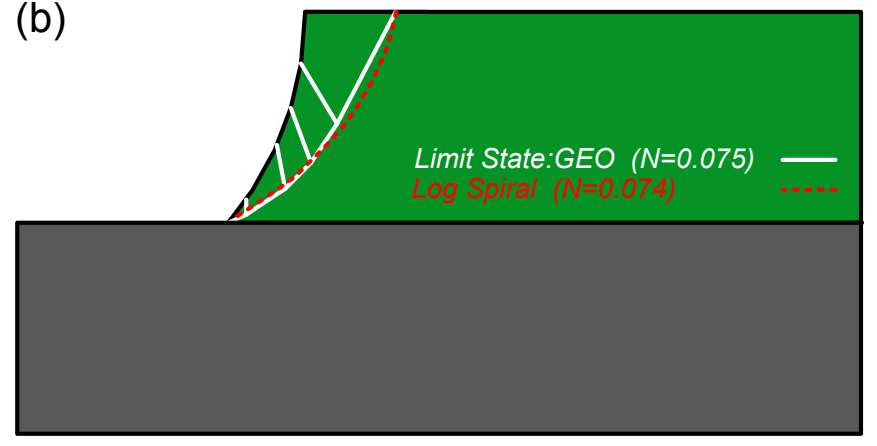

Fig. 8. Comparison of critical slip surfaces from the current study versus upper-bound solution in limit analysis with discontinuity layout optimization for $\phi=30^{\circ}$ : a) $\beta=\square 0^{\circ}$; b) $\beta=70^{\circ}$. 